
\title{
28 Research Square \\ Partitioning of Benzene in Soil Environment: The Critical Factor of Exposure
}

\section{Ruihuan Zhang}

Beijing Municipal Research Institute of Environmental Protection https://orcid.org/0000-0003-44862916

\section{Shijie Wang}

Beijing Municipal Research Institute of Environmental Protection

\section{Lin Jiang ( $\nabla$ jianglin@cee.cn )}

Beijing Municipal Research Institute of Environmental Protection https://orcid.org/0000-0002-6982-

0758

\section{Wenyu Zhang}

Beijing Municipal Research Institute of Environmental Protection

\section{Quankai Fu}

Beijing Municipal Research Institute of Environmental Protection

\section{Lin Ma}

Beijing Municipal Research Institute of Environmental Protection

\section{Maosheng Zhong}

Beijing Municipal Research Institute of Environmental Protection

\section{Research}

Keywords: organic pollutants, contaminated soil, moisture, organic matter, partitioning

Posted Date: August 13th, 2021

DOI: https://doi.org/10.21203/rs.3.rs-754331/v1

License: (a) This work is licensed under a Creative Commons Attribution 4.0 International License.

Read Full License 


\section{Abstract}

Background: From the perspective of contaminated sites risk assessment, vapor-solid interface adsorption of volatile organic compounds (VOCs) in soil is thought to play a pivotal role because this greatly affects the release of VOCs into soil gas thus affecting the concentrations of intrusion and human exposure. Understanding the significance requires quantifying different forms of VOCs that occur in soil, but no relevant models have included the vapor-solid interface adsorption yet.

Methods: This paper proposes the multiphase partitioning equilibrium (MPE) model that integrates vaporsolid adsorption phase for the first time. The MPE model establishes the quantitative relationship between the total VOC mass in soil and the mass in various partitioning phases. An equilibrium partitioning experiment was designed to verify the validity of the MPE model.

Results: The error of the MPE model was basically within an order of magnitude. It also revealed that that the vapor-solid interface adsorption dominates benzene uptake in dry soil, but as reducing adsorption of soil minerals (vapor-solid interface adsorption) by increasing humidity, uptake by partitioning into the soil organic matter (OM) gradually dominates. Soil moisture was demonstrated the controlling factor that affects the partitioning. It was distinct that exposure concentration of benzene in indoor air rises from $0.0013 \mathrm{mg} / \mathrm{m}^{3}$ to $0.0070 \mathrm{mg} / \mathrm{m}^{3}$ when the sandy soil relative saturation increases an order of magnitude from 0.01 .

Conclusion: This study confirms the significance of VOCs partitioning in soil environment for human health exposure, in addition to frequently-mentioned exposure parameters and building parameters. The MPE model gives accurate mass/concentration prediction of VOCs phases in the soil system, and the relationship between exposure and soil moisture was proved.

\section{Introduction}

Volatile organic compounds (VOCs) that enter the soil at contaminated sites can be transferred to the surrounding air and cause threats to human health (Thompson et al., 2014; Aschengrau et al., 2015; EPA, 2015a, 2015b; Zhang et al., 2019a). The partitioning of VOCs in soil, which directly affects the intrusion concentration and the human health risk, is a composite physical/chemical behavior usually containing vapor-solid interface adsorption, gas-liquid interface adsorption, liquid-solid interface adsorption and the gas phase and dissolved phase (Pennell et al., 1992; Unger et al., 1996). Among all these phases, the vapor-solid interface adsorption is extremely important (Cheng et al., 2021; Chiou and Shoup, 1985; Unger et al., 1996). It is of great significance to understand and quantify the inter-phase distribution of VOCs in soil especially the vapor-solid interface adsorption, which is conducive to make scientific decisions on site remediation or risk control measures.

Park proposed a three-phase equilibrium model in 1999, and the equations that govern the equilibrium partitioning between the phases are the linear sorption partitioning equation normalized with respect to OC content and Henry's Law (Karickhoff et al., 1979; Park, 1999). The form of the formula is simple and 
easy to embed into the formula of exposure risk assessment (Connor et al., 2007; MEEPRC, 2014). Many experiments subsequently indicated that soil particles can produce blocking effect on organic pollutants through physical embedding, chemical adsorption and micro-pore blocking so that the desorption process of organic pollutants in soil does not always follow the linear relation (Kan et al., 1994; Hunter et al., 1996; Kan et al., 1997; McGroddy and Farrington, 1997). Kan et al. quantified the desorption process of organic pollutants in soil by batch adsorption/desorption experiments and established a dual-phase equilibrium desorption model (DED model) based on solid-liquid nonlinear desorption behavior (Kan et al., 1998). Zhang et al. derived a new three-phase equilibrium partitioning model based on the DED model and validated it with data sets collected from several contaminated sites (Zhang et al., 2019b). However, both models ignored the vapor-solid interface adsorption of VOCs. Some studies have pointed out that in the unsaturated soils, VOC sorption is primarily a function of available mineral surface area, and OC plays only a minor role in sorption at low moisture contents (Yardon et al., 1989; Steinberg and Kreamer, 1993; Steinberg et al., 1996). For the site soil, the soil moisture content is highly heterogeneous from the saturated capillary zone to the dry zone near the surface. It showed that for dry soil, the main mechanism of VOC gas adsorption is the interface adsorption by soil minerals; with increasing soil moisture, highly polar water molecules can occupy the active adsorption sites on the surface of soil minerals through strong competitive adsorption, thus significantly inhibiting the surface adsorption process of VOC molecules (Chiou et al., 1985; Ong and Lion, 1991). Thus, vapor-solid interface adsorption is particularly important in VOCs partitioning in soil.

Several adsorption isotherms were used to describe the behavior of the interface adsorption before (Fan et al., 2020; Li et al., 2020; Wang et al., 2020; Bradney et al., 2019; Conde-Cid et al., 2019a, 2019b; Zhang et al., 2019c). For the adsorption happened in soil, BET model is considered to be the most accurate (Brunauer et al., 1938; Chiou et al., 1985; Unger et al., 1996). A static headspace gas adsorption experiment was designed to validate the BET isotherm in predicting vapor-solid interface adsorption of soil, and a multiphase partitioning equilibrium (MPE) model imbedded with the BET isotherm was deduced. The model was then validated by the data obtained from an equilibrium partitioning experiment. Further multiphase partitioning of benzene in different soils was quantitatively determined and the effects of soil moisture and OC content on the partitioning of benzene were explored by the MPE model subsequently. The new model is not only able to accurately predict the mass and concentration of

each phase of VOCs particularly in an unsaturated soil system, but also provide a theoretical basis for the comprehensive understanding of VOC partitioning in soil, such as the role of vapor-solid interface adsorption and the effect of soil moisture.

\section{Materials And Methods}

\subsection{Soil Collection}

Clayey soil and sandy soil were collected from a chemical plant in Shenyang city, China. The silty soil was collected from a contaminated site that was used as a gas chemical plant in Taiyuan city, China. Sandy soil is the soil that particles larger than $2 \mathrm{~mm}$ in diameter account for less than $50 \%$ of the total 
mass while the particles larger than $0.075 \mathrm{~mm}$ exceed $50 \%$ of the total mass. Silty soil is a type of soil that particles greater than $0.075 \mathrm{~mm}$ do not exceed $50 \%$ of the total mass while the plasticity index equals or less than 10 . Soil with plasticity index greater than 10 is identified as clayey soil. This classification is based on the standard issued by Ministry of Housing and Urban-Rural Development of the People's Republic of China in 2009 (MOHURD, 2009). Benzene was determined the only soil pollutant in the two sites by previous investigations. An SH-30 model rig method (a gravity impact drill) was applied to drill the soil cores at each site and we sampled from the middle of the original core after it was collected and cut open. It should be noted that soil samples were both collected from the polluted and non-polluted areas. The non-polluted soils were used for the static headspace experiment and the polluted soils were used for the equilibrium partitioning experiment. The group identified samples with labels like sampling date and boring number prior to transporting them. Then the group reserved and transported these samples in sealed wide-mouth bottles. The bottles were arranged into large plastic boxes and transported to laboratories subsequently. The preservation and transportation of soil samples were followed the standard practices released by ASTM in 2014 (ASTM, 2014).

\subsection{Static Headspace Experiment}

After air drying, sorting and sieving, the non-polluted soil was placed on a stainless steel tray and dried in an oven at $105^{\circ} \mathrm{C}$. Samples were taken at $24 \mathrm{~h}, 48 \mathrm{~h}$ and $72 \mathrm{~h}$ respectively during drying for background pollution analysis. The result showed that there was no background pollution after 48-hour drying. Then, the soil was quickly transferred to clean dry ground glass bottle and sealed with sealing film. The bottle was placed in a constant temperature dehumidification box $\left(t=25^{\circ} \mathrm{C}\right)$.

Adding every $10 \mathrm{~g}$ of dried soil to empty brown headspace bottles, clean and dry inner tubes were placed upright in the bottle. The bottle caps were equipped with airtight valves which connected to the tubes. The empty bottles were weighed before and after the filling procedure, and the accurate mass of the soil samples in the bottle could be calculated by the difference method.

Benzene is the pollutant of concern in this study. A gradient mass of benzene was transferred through the tubes of the headspace bottles. After the addition the valves were quickly closed and the bottles were weighed again. The mass of benzene injected to the bottles could be calculated by the difference method. Headspace bottles were placed in a constant temperature oscillation box $\left(t=25^{\circ} \mathrm{C}\right)$ for distribution reactions. The pre-experiment results showed that the partitioning of benzene in the headspace bottle could achieve equilibrium within $24 \mathrm{~h}$. Therefore, the airtight headspace bottles were placed in the constant temperature oscillation box for more than $24 \mathrm{~h}$. After opening the valve switch on the cap one by one, $0.1 \mathrm{~mL}$ of headspace gas was transferred to the gas chromatograph-mass spectrometer by a gas-tight syringe to determine the gas concentration in the headspace at equilibrium. The valve push rods were pushed to close the valves immediately after the gas-tight syringe probe completed the sampling. After an interval of $0.5 \mathrm{~h}$, parallel samples were taken repeatedly. Then, the bottle caps were slowly unscrewed, and a precision pipette gun was used to quickly inject $10 \mathrm{~mL}$ of methanol to fully wet the soil in every bottle. An air pipe was used to inject high-purity nitrogen to purge 
the headspace gas in the bottles. After the air pipe was removed, the headspace bottles were sealed quickly and placed in an incubator $\left(t=25^{\circ} \mathrm{C}\right)$ for $24 \mathrm{~h}$.

A micro-liquid sampler was used to puncture through the silica gel spacers of the bottle caps, and $1 \mu \mathrm{L}$ of the methanol supernatant was accurately measured and injected into the gas chromatograph-mass spectrometer to determine the benzene concentration in the extract liquor. After half an hour, parallel samples were taken repeatedly for analysis.

\subsection{Equilibrium Partitioning Experiment}

The benzene-polluted soil sample was moved from the refrigerator $\left(\mathrm{t}=4^{\circ} \mathrm{C}\right)$ and transferred in the incubator $\left(t=25^{\circ} \mathrm{C}\right)$ for approximately $6 \mathrm{~h}$. Empty headspace bottles were marked a serial number and weighed. A handle and non-disturbance sampler was used to transfer approximately $10 \mathrm{~g}$ of soil for every headspace bottle. The sampling and analysis steps were identical with the static headspace experiment.

\subsection{Model Development}

2.4.1 Adsorption on the Surface of Soil Particles. The adsorption of VOCs on the soil particles surface can be divided into adsorptions on the liquid-solid interface and vapor-solid interface. Liquid-solid interface adsorption by soil OM is expressed by the DED model as follows, which considers the irreversible adsorption of organic compounds on the soil surface and shows great agreement with the experimental data (Kan et al., 1998):

$$
C_{s 1}=K_{O C} \cdot f_{O C} \cdot C_{w}+\frac{K_{O C}^{2 n d} \cdot f_{O C} \cdot q_{\max }^{2 n d} \cdot f \cdot C_{w}}{q_{\max }^{2 n d} \cdot f+K_{O C}^{2 n d} \cdot f_{O C} \cdot C_{w}}
$$

where $\mathrm{C}_{\mathrm{s} 1}$ is the liquid-solid sorption concentration $(\mathrm{mg} / \mathrm{kg}), \mathrm{C}_{\mathrm{W}}$ is the aqueous-phase solute concentration (mg/L), $\mathrm{K}_{\mathrm{OC}}$ and $\mathrm{K} 2 \mathrm{nd}$ oc represent the $\mathrm{OC}$ normalized partition coefficients for the first and second compartments $(\mathrm{L} / \mathrm{kg})$, respectively, $f_{O C}$ is the $\mathrm{OC}$ content of soil $(\mathrm{g} / \mathrm{g}), \mathrm{q} 2 \mathrm{nd}$ max is the maximum sorption capacity of the second compartment $(\mathrm{mg} / \mathrm{kg})$, and $\mathrm{f}$ represents the fraction of the second compartment that is saturated upon exposure (usually $0 \leq f \leq 1$ ). The values and corresponding sources of the above parameters are given in Table A.7 of the supplementary material.

Brunauer, Emmett, and Teller extended the Langmuir model to include multilayer adsorption (Brunauer et al., 1938). The BET adsorption model assumes that the theory of the Langmuir equation applies to each adsorption layer and that the heat of adsorption of the first layer has a distinct value, while that of the second and higher layers are equivalent. The BET isotherm has been proven to have an excellent goodness of fit to the measured data of organic compounds adsorbed on soil (Brunauer et al., 1938, Chiou et al., 1985, Unger et al., 1996). The expression is as follows: 


$$
C_{s 2}=\frac{C_{\text {Movo }} K\left(P / P_{0}\right)}{\left(1-P / P_{0}\right)\left[1+(K-1)\left(P / P_{0}\right)\right]}
$$

where $\mathrm{C}_{\mathrm{s} 2}$ is the gas-solid sorption concentration of benzene in soil $(\mathrm{mg} / \mathrm{kg}), \mathrm{P}$ is the partial pressure of the sorbate in the gas phase $(\mathrm{Pa}), \mathrm{P}_{0}$ is the saturation pressure of the compound $(\mathrm{Pa}), \mathrm{K}$ is the affinity constant exponentially related to the heat of adsorption (unitless), and $\mathrm{C}_{\mathrm{MONO}}$ is the sorbed concentration $(\mathrm{mg} / \mathrm{kg})$.

When both sides of the equation are divided by $\mathrm{P}_{0}$ and $\mathrm{M}$, the expression of the ideal gas law can be rewritten as:

$$
\frac{p}{p_{0}}=C_{s g} \cdot \frac{R T}{p_{0} M}
$$

where $C_{s g}$ is the vapor-phase concentration of organic compounds $(\mathrm{mg} / \mathrm{L}), \mathrm{R}$ is the gas constant $(8.3145$ $\mathrm{J} \cdot \mathrm{mol}-1 \cdot \mathrm{K}-1), \mathrm{T}$ is the system temperature $(\mathrm{K})$, and $\mathrm{M}$ is the molecular mass of the compound $(\mathrm{g} / \mathrm{mol})$. A parameter $\mu$ is defined as follows:

$$
\mu=\frac{R T}{p_{0} M}
$$

Then, the expression of the BET isotherm can be rewritten as:

$$
C_{s 2}=\frac{\mu C_{s g} C_{M O V O} K}{\left(1-\mu C_{s g}\right)\left[1+\mu C_{s g}(K-1)\right]}
$$

2.4.2 Mass balance. A mass balance accounts for solute in each phase of the system, including the mass of VOC in the vapor phase and the liquid phase, adsorbed at the solid-vapor interface and the solid-liquid interface and the gas-liquid interface, condensed in micro-pores. The quantitative relation of gas-liquid sorption can be expressed by the Gibbs absorption equation. However, this part has been hardly proven because the thickness of the effective interface is not more than a few molecules. Solute condensation is only significant when both $\mathrm{RS}=0$ and $\mathrm{P} / \mathrm{P}_{0}>0.4$, as determined by the Kelvin equation (Unger et al., 1996). Therefore, valid phases generally include four components.

$$
C_{T} \cdot \rho=C_{s g} \cdot \theta_{a \dot{v}}+C_{w} \cdot \theta_{w}+C_{s 1} \cdot\left(1-f_{v}\right) \cdot \rho+C_{s 2} \cdot f_{v} \cdot \rho
$$


where $\mathrm{C}_{\mathrm{T}}$ represents the total soil concentration $(\mathrm{mg} / \mathrm{kg}), \rho$ represents the dry soil bulk density $(\mathrm{kg} / \mathrm{L}), \theta_{\text {air }}$ represents the volumetric air content, $\theta_{\text {water }}$ represents the volumetric water content, and $f_{v}$ is the fraction of the soil surface exposed to the vapor phase and is given by $\mathrm{N}_{2}$-BET adsorption and mercury intrusion analysis of the soil (the results for each of the soils were showed in the section 3 of the supplementary material) (ISO, 2016, 2007, 2006). Based on the soil pore size distribution and soil moisture content, $f_{v}$ value can be calculated. The calculation was introduced by Unger before (Unger et al., 1996).

Compared to the existing models quantifying the partitioning of VOC in soil, a noteworthy superiority of this MPE model is that VOC adsorption at the soil gas-solid interface is involved. By integrating Henry's law, the DED model, the transformed BET isotherm and mass conservation equation, the proposed model contains all dominating and potential phases of VOC uptake by soil.

2.4.3 Form of Solution. Defining $\mathrm{C}_{\mathrm{T}}$ as the independent variable and $\mathrm{C}_{\mathrm{sg}}$ as the dependent variable, the solution becomes a mathematical problem of solving a quartic equation with one variable. Here, the Ferrari method was applied to solve the equation and the solutions are as:

$$
C_{\mathrm{Sg}}=\frac{ \pm \sqrt{\frac{1}{4} b^{2}-c+C_{T}}-\frac{1}{2} b \pm \sqrt{\left(\frac{1}{2} b-\sqrt{\frac{1}{4} b^{2}-c+C_{T}}\right)^{2}-4\left(\frac{1}{2} C_{T}-\sqrt{\frac{1}{4} C_{T}^{2}-d}\right)}}{2}
$$

The lowercases in the equation are assumed:

$$
\begin{aligned}
& b=\frac{(C E+B C F)(D H-\mu H)-\mu D(A E+A B F)-A C D F \mu+C D H \rho \mu x}{-\mu D(C E+B C F)} \\
& c=\frac{H^{2}(C E+B C F)+(A E+A B F)(D H-\mu H)+C G+A D H \rho \mu x}{-\mu D(C E+B C F)} \\
& d=\frac{A H^{3} \rho x}{\mu D(C E+B C F)}
\end{aligned}
$$

and the upper cases in equation (8) (11) are assumed: 


$$
\begin{aligned}
& A=H \cdot q_{\max }^{2 n d} \cdot f \\
& B=K_{O C} \cdot f_{O C} \\
& C=K_{O C}^{2 n d} \cdot f_{O C} \\
& D=\mu(K-1) \\
& E=H \theta_{a \dot{ }}+\theta_{w} \\
& F=\left(1-f_{v}\right) \rho \\
& G=\mu H C_{M O N O} K f_{v} \rho
\end{aligned}
$$

To a quartic equation there are four solutions which may include complex or negative solutions. It is necessary to take the solution with a real and positive number as the final solution. The form of the final expression is the Ferrari's solution which contained a bulk of parameters relative to the pollutant and soil. The detailed solution process is given in the section 1 of the supplementary material.

\subsection{Analytical Methods}

The benzene in the soil gas was determined by gas chromatography with flame ionization detection (GCFID) (7894A, Agilent, USA). The length, diameter and film thickness of the gas chromatography column were $30 \mathrm{~m}, 0.32 \mathrm{~mm}$, and $0.25 \mathrm{~mm}$, respectively (19091J-413, Agilent, USA). The inlet and detector temperatures were $200^{\circ} \mathrm{C}$ and $250^{\circ} \mathrm{C}$, respectively. The gas sample injection volume was $1 \mathrm{~mL}$ with the split ratio of 10:1. Five-point calibration curves were prepared using a liquid phase standard before conducting gas sample analysis.

\subsection{Quality Control}

During the static headspace experiment, the headspace concentration was measured at equilibrium. The volume capacity of the glass bottle was known as well as the weight of the added soil, so the volume of the headspace could be calculated. After collecting the headspace gas samples, the sealing film on the glass bottle was opened, and the headspace gas in the bottle was rapidly expelled with a stream of nitrogen. The benzene was extracted from $10 \mathrm{~mL}$ of methanol, and this fraction of the mass plus the mass of benzene in the headspace gas was defined as the recovered mass. Compared to the mass initially added, the recovery rate was basically higher than $75 \%$ (arithmetic mean $=78.19 \%$, median $=$ 76.89\%). In addition, the relative average deviations (RADs) of parallel samples collected during the static headspace experiment for determining the gas concentration of benzene were all in the range of $-7 \%$ to 
$7 \%$, and the RADs of parallel samples of methanol supernatant analysis were in the range of $-14 \%$ to $14 \%$. Detailed data are found in the section 2 of the supplementary material.

\section{Results And Discussion}

\subsection{Static Headspace Experiment}

The masses of benzene adsorbed by the oven-dry soils at different relative vapor pressures $\left(P / P_{0}\right)$ were determined by the headspace adsorption experiment. In Fig. 1, the experimental results for three kinds of soils (sandy soil, silty soil and clayey soil) are shown as dots. The values represented by the dots are the average values of parallel samples. Three gas-solid adsorption isotherms (linear, Langmuir and BET) were used to fit the experimental data. The isotherm functions have been given in the Sect. 5 of the supplementary material.

From Fig. 1, the relative equilibrium partial pressure of benzene in the headspace adsorption experiment was between 0.00001 and 0.01 , and the corresponding range of benzene vapor-phase concentration was between $4 \mathrm{mg} / \mathrm{m}^{3}$ and $4000 \mathrm{mg} / \mathrm{m}^{3}$. The relationship obtained from the adsorption was nonlinear over the range of relative vapor pressures investigated, which was similar to a previous experiment utilizing $p$ xylene (Pennell et al., 1992). The three commonly used adsorption isotherms can sufficiently fit the gassolid adsorption process. The fitting parameters are shown in Table 1. It was notable that in Fig. 1(d) at the same relative vapor pressures, the gas-solid adsorption concentration of clayey soil was higher than that of the other two kinds of soils. A possible explanation is that the particles of clayey soil are finer than those of silty soil and sandy soil, and contribute more specific surface area. The specific surface areas of clayey soil, silty soil and sandy soil are $23.06 \mathrm{~m}^{2} / \mathrm{g}, 7.65 \mathrm{~m}^{2} / \mathrm{g}$ and $2.75 \mathrm{~m}^{2} / \mathrm{g}$ respectively, revealed by $\mathrm{N}_{2}$ BET adsorption and mercury intrusion analysis. Besides, mineralogical composition may also affect the soil adsorption capacities. Petersen et al. found that the values of solid/vapor partition coefficient did not correlate well with specific surface area and concluded the VOC sorptive affinity for different minerals may be dependent more on the mineralogical composition (Petersen et al., 1995). 
Table 1

Fitting parameters of three adsorption isotherms (linear, Langmuir and BET) to the experimental data in Fig. 1

\begin{tabular}{|lllll|}
\hline & Isotherms & Fitting parameter & $\mathbf{R}^{2}$ & $\mathbf{P}$ \\
\hline Sandy soil & Linear & $\mathrm{K}_{\mathrm{p}}=0.0917$ & 0.978 & $<0.001$ \\
\cline { 2 - 5 } & Langmuir & $\mathrm{C}_{\mathrm{m}}=0.7114 ; \mathrm{b}=0.2118$ & 0.993 & $<0.001$ \\
\cline { 2 - 5 } & BET & $\mathrm{C}_{\mathrm{MONO}}=0.6871 ; \mathrm{K}_{\mathrm{B}}=89.8325$ & 0.993 & $<0.001$ \\
Silty soil & Linear & $\mathrm{K}_{\mathrm{p}}=0.3971$ & 0.94 & $<0.001$ \\
\cline { 2 - 5 } & Langmuir & $\mathrm{C}_{\mathrm{m}}=2.2451 ; \mathrm{b}=0.3699$ & 0.961 & $<0.001$ \\
\cline { 2 - 5 } & BET & $\mathrm{C}_{\mathrm{MONO}}=2.1894 ; \mathrm{K}_{\mathrm{B}}=155.6297$ & 0.961 & $<0.001$ \\
Clayey soil & Linear & $\mathrm{K}_{\mathrm{p}}=0.5342$ & 0.921 & $<0.001$ \\
\cline { 2 - 5 } & Langmuir & $\mathrm{C}_{\mathrm{m}}=2.1324 ; \mathrm{b}=0.8698$ & 0.945 & $<0.001$ \\
\cline { 2 - 5 } & BET & $\mathrm{C}_{\mathrm{MONO}}=2.0969 ; \mathrm{K}_{\mathrm{B}}=364.53$ & 0.945 & $<0.001$ \\
\hline
\end{tabular}

From Table 1, for all three soils, the adsorption isotherms fit the adsorption of benzene onto dry soil well. The fitting degrees of the Langmuir isotherm and BET isotherm are better than that of the linear isotherm. Notably, the fitting degrees of the Langmuir and BET isotherms are fairly close. The reason lies in the BET model being developed based on the Langmuir isotherm by assuming that the adsorption heat of the second or other layers is equal to the liquefaction heat of the adsorbate, and the single-layer adsorption theory is extended to the multilayer adsorption theory (Brunauer et al., 1938). Compared with the adsorption capacity of the soil particles corresponding to the maximum pollution concentration in the experiment, it was found that the extent of adsorption did not exceed the adsorption capacity of monolayer.

\subsection{Model Calibration}

Based on the total soil concentrations, the gas concentrations of benzene can be predicted by the MPE model. The data was obtained from the equilibrium partitioning experiment introduced in the Sect. 2.3. Figure 2 compares the predicted soil gas concentrations by the MPE model with the measured headspace concentrations. From the Fig. 2, the error is basically within an order of magnitude in all three soils. This demonstrates that the MPE model is reliable in this study. The parameters and their values used to derive the predicted gas concentration were showed in the Sect. 4 of the supplementary material.

\subsection{Effect of Soil Moisture on Partitioning and Exposure}

The soil moisture directly affects the soil pores filling degree with water molecules. When the moisture increases, water molecules follow the law of filling soil pores from small to large and occupy the mineral surface of solid particles, resulting in a decrease in the effective adsorption capacity of the gas-solid 
phase (Rasmussen et al., 1990; Smith et al., 1990; Brusseau, 1991). The sorption of organic vapors is strongly suppressed by water because of the adsorptive competition on minerals (Chiou and Shoup, 1985).

RS has an evident negative correlation with $f_{v}$. From Fig. 3(a), when the RS was 0, i.e., the system was under completely dry condition, the solid adsorption capacity reached the maximum $\left(f_{v}=1\right)$. Some previous studies have revealed that the amount of moisture required to saturate the mineral surfaces is far less than that required to occupy the whole pores of soil particles, and although the soil may be considered unsaturated, the mineral surfaces of the soil have actually been saturated with water molecules (Smith et al., 1990). This suggested that $f_{v}$ should decrease to 0 before the RS the reached 1 , and the indication of Fig. 3(a) was consistent with the conclusion. When the RS increased from 0 to 0.1 , $f_{v}$ decreased sharply especially in sandy soil and silty soil. When the RS reached $10 \%, f_{v}$ decreased to less than 0.1 indicating that the proportion of benzene existing in soil due to vapor-solid interface adsorption was quite little. Chiou also found that water vapor sharply reduced the sorption capacities of organic compounds in dry soil (Chiou and Shoup, 1985). The reason for the rapid decline in $f_{v}$ was that water molecules follow the order of filling soil pores from small to large, while small pores contribute more to the specific surface area than macro-pores. Thus, the soil surface area is quickly occupied by water molecules when more water molecules enter.

Figure 3(b) shows that the capacity of vapor-solid interface adsorption (dry soil) was approximately two orders of magnitude higher than that of liquid-solid interface adsorption (saturated soil) at the same relative concentration of benzene predicted by the MPE model. This prediction was similar to Kobayashi's experimental finding that the adsorbed amount of tetrachloroethylene (TCE) to wet soil decreased to $1 / 300-1 / 10000$ of the amount adsorbed to dry soil, showing that the soil moisture greatly influenced the adsorbed amount (Kobayashi et al., 2003).

Soil moisture content was proven a critical factor in determining the contributions of mineral and organic soil fractions to soil uptake of nonionic organic compounds (Chiou and Shoup, 1985). Figure 4 (a-c) shows similar trends among the three soils that almost all of the benzene in the soil adsorbed on the mineral interface when the soil system was dry. Moreover, the mass of the liquid-solid adsorption and solution phase were both null, and the mass of the gas phase was very little. When the RS increased from 0 , the mass of the liquid-solid adsorption increased rapidly while the mass of gas-solid adsorption showed the opposite trend. The variation was similar to the change in $f_{v}$ with RS as discussed in Fig. 3(b). As adsorption by soil minerals is further reduced by increasing amounts of humidity, uptake by partitioning into the soil OM increasingly becomes a controlling factor (Chiou and Shoup, 1985). When benzene in the soil was present mainly in the liquid-solid adsorption phase, approximately $20 \%$ of benzene was in the dissolved phase, but benzene was almost absent in vapor-solid adsorption phase and gas phase. This coincides with the statement of Goss that adsorption to minerals does not play a role at all in soils at RH $>98 \%$ (Goss et al., 2004). It can be concluded from the figures that the interface adsorption (vapor-solid interface and liquid-solid interface) of soil particles dominated throughout the 
period of RS. In the panels ( $d-f, j-1)$, the assumed total soil concentration of benzene is $7.27 \mathrm{mg} / \mathrm{kg}$. It is noteworthy that under dry conditions the vapor concentration was not as high as expected from Fig. 4 (df). This prediction was in agreement with the observation from a previous study that dry soil surfaces may effectively suppress such transport by adsorption (Goss et al., 2004). However, the concentration predicted by the model incorporating only liquid-solid interface adsorption was negatively correlated with $\mathrm{RS}$, and when the RS equals to 0 , the predicted vapor concentration was the highest (Fig. $4(\mathrm{j}-\mathrm{I})$ ). The percentages of mass of benzene in each phase predicted by the two models were also quite different. The model incorporating only liquid-solid interface adsorption predicted that the mass of liquid-solid interface adsorption was the highest when the RS was 0 and decreased with increasing RS (Fig. 4 (g-i)), which was obviously not what was experimentally observed. Figure 4 also proved that gas-solid interface adsorption dominates the contribution of VOC uptake by the soil system when the RS was low. In the case of extremely dry soil, the adsorption mass of the gas-solid interface even reached nearly $100 \%$. Thus, it is also an evidence of necessarily imbedding gas-solid adsorption into the partitioning model.

VOCs in soil can migrate upward into indoor or outdoor spaces, causing threaten to human health. The effect of soil moisture on exposure concentration is indirect. Generally speaking, soil moisture affects the exposure concentration in two ways. On the one hand, as discussed before that soil moisture greatly affects the partitioning of VOCs in the soil environment, there is an obvious change in the vapor concentration of pollutants, i.e., source concentration in risk assessment models, because of the soil moisture. On the other hand, moisture affects the migration of VOCs in soil, which is reflected in the effective diffusion coefficient in migration models. Figure 5 shows how the indoor air concentration of benzene changes with RS in the scenario of vapor intrusion. The model and the specific parameter values are all followed by the guideline issued by MEEPRC (MEEPRC, 2014).

From Fig. 5, the indoor air concentration increases at first and then decreases with the increase of RS. It should be noted that the effective diffusion coefficient decreases when moisture increases. However, as showed in Fig. 4 (d-f), the vapor concentrations of benzene increase sharply in the range 0 to 0.1 of RS and then basically doesn't change. Both the two factors donate the change in three typical soils in Fig. 5 . It is distinct that exposure concentrations rise up quite sharply when RS increases from 0 . For example, Fig. 5(a) shows that the exposure concentration in indoor air rises from $0.0013 \mathrm{mg} / \mathrm{m}^{3}$ to $0.0070 \mathrm{mg} / \mathrm{m}^{3}$ when RS increases an order of magnitude from 0.01 . When RS is above 0.8 , benzene in soil can hardly invade into the indoor air, because the migration of benzene in the soil is extremely slow at this time. This result is very different from the existing exposure models but in agreement with the experiment findings.

\subsection{Effect of Organic Matter on Partitioning and Exposure}

A common notion is that soil OM dominates the sorption process of VOCs in saturated soils (Steinberg et al., 1996). However, the effect of OM content variation on the adsorption capacity in saturated or unsaturated soils is rarely reported. By the MPE model developed herein, the proportion of masses sorbed at the solid-vapor interface and solid-liquid interface in the clayey soil of the Sect. 3.4 were predicted when increasing $f_{O C}$ from 0.001 to 0.1 . 
Soil OM does not affect vapor-solid interface adsorption directly but affects liquid-solid interface adsorption. From Fig. 6 , it is found that even when increasing the soil OM 100-fold, the partitioning of benzene in soil was not obviously changed in either saturated or unsaturated soils (the scale of the x-axis has been shown logarithmically to highlight the variation in interface sorption caused by $f_{O C}$ ). Steinberg compared the sorption of trichloroethylene (TCE) and benzene to unmodified soil with sorption onto the same soil that was alternately treated with hydrogen peroxide (to remove OC) or with humic acids (to add $\mathrm{OC}$ ) and found that $\mathrm{OC}$ plays only a minor role in sorption at low moisture contents, which is similar to the prediction in Fig. 6 (Steinberg et al., 1996). Besides, soil OM has little effect on the migration of benzene in soil, the effect of OM content on exposure is far less than that of moisture.

\section{Conclusions}

So far the assessment of VOC-contaminated sites in China is mainly conducted by analyzing the VOC soil concentration guided by the national administrative department. However, vapor-phase diffusion and advection through the vadose zone can be major pathways of contaminant migration. The process of converting the soil concentration to the soil gas concentration is critical; otherwise, the model is prone to overestimate or underestimate the risk of the site, which will lead to incorrect judgment on subsequent site management and development decisions. The proposed MPE model giving accurate mass prediction of each phase of VOCs in a soil system has apparent practical applications. Besides, the model also provides a relatively reliable basis for the comprehensive understanding of VOC partitioning in soil, such as the role of vapor-solid interface adsorption and the effect of soil moisture. In particular, the model has its greatest utility for soils especially in arid environments.

\section{Declarations}

\section{AUTHOR INFORMATION}

\section{* Corresponding Author}

Lin Jiang (Email: jianglin@cee.cn)

\section{ORCID}

Lin Jiang: 0000-0002-6982-0758

Ruihuan Zhang: 0000-0003-4486-2916

Competing interests

The authors declare that they have no competing interests.

\section{Authors' contributions}


Writing - Original Draft: RZ, Writing - Review \& Editing: LJ, RZ, Methodology: LJ, RZ, QF, MZ, Formal analysis: RZ, Visualization: RZ, QF, Conceptualization: LJ, Resources: LJ, Supervision: LJ, MZ, SW, Investigation: QF, WZ, LM, Project administration: SW. All authors read and approved the final manuscript.

\section{Supplementary Information}

The online version contains supplementary material available at

\section{Ethics approval and consent to participate}

Not applicable

\section{Availability of data and materials}

The datasets during and/or analysed during the current study available from the corresponding author on reasonable request.

\section{Funding}

This work was supported by the Ministry of Science and Technology of the People's Republic of China [grant numbers 2018YFC1800703, 2018YFC1803001].

\section{References}

1. ASTM (American Society of Testing Materials) (2014). Standard practices for preserving and transporting soil samples, D4220/D4220M-14. https://www.astm.org/Standards/D4220.htm.

2. Aschengrau, A., Winter, M. R., Vieira, V. M., Webster, T. F., Janulewicz, P. A., Gallagher, L. G., Weinberg, J., Ozonoff, D. M (2015). Long-term health effects of early life exposure to tetrachloroethylene (PCE)contaminated drinking water: a retrospective cohort study. Environmental Health, 14, 36. DOI: 10.1186/s12940-015-0021-z.

3. Bradney, L., Wijesekara, H., Palansooriya, K. N., Obadamudalige, N., Bolan, N. S., Ok, Y. S., Rinklebe, J., Kim, K., Kirkham, M.B (2019). Particulate plastics as a vector for toxic trace-element uptake by aquatic and terrestrial organisms and human health risk. Environment International, 131, 104937. DOI: 10.1016/j.envint.2019.104937.

4. Brusseau, M. L (1991). Transport of Organic Chemicals by Gas Advection in Structured or Heterogeneous Porous Media: Development of a Model and Application to Column Experiments. Water Resources Research, 27 (12), 3189-3199, DOI: 10.1029/91wr02195.

5. Brunauer, S., Emmett, P. H., Teller, E (1938). Adsorption of gases in multimolecular layers. Journal of the American Chemical Society, 60 (2), 309-319, DOI: 10.1021/ja01269a023.

6. Cheng, J., Ye, Q., Lu, Z., Zhang, J., He, Y (2021). Quantification the sorption of mineral to organic pollutants by improved mathematic model accounting for associations between mineral and soil 
organic matter. Environmental Pollution, 280, 116991. DOI: 10.1016/j.envpol.2021.116991.

7. Conde-Cid, M., D Fernández-Calvio, JC Nóvoa-Muoz, A Núez-Delgado, E Lvarez-Rodríguez (2019a). Experimental data and model prediction of tetracycline adsorption and desorption in agricultural soils. Environmental Research, 177, 108607. DOI: 10.1016/j.envres.2019.108607.

8. Conde-Cid, M., Ferreira-Coelho, G., A Núez-Delgado., D Fernández-Calvio., MJ Fernández-Sanjurjo (2019b). Competitive adsorption of tetracycline, oxytetracycline and chlortetracycline on soils with different ph value and organic matter content. Environmental Research, 178, 108669. DOI: 10.1016/j.envres.2019.108669.

9. Connor, J.A., Bowers, R.L., McHugh, T.E., Spexet (2007), A.H. RBCA Tool Kit for Chemical Releases: Risk-based Corrective Action Tool Kit Version 2, GSI Environmental Inc. Press: Texas, U.S.

10. Chiou, C. T., Shoup, T. D (1985). Soil sorption of organic vapors and effects of humidity on sorptive mechanism and capacity. Environmental Science \& Technology, 19 (12), 1196-1200, DOI: 10.1021/es00142a010.

11. Fan, J., Cai, C., Chi, H., Reid, B. J., Coulon, F., Zhang, Y., Hou, Y (2020). Remediation of cadmium and lead polluted soil using thiol-modified biochar. Journal of Hazardous Materials, 122037. DOI: 10.1016/j.jhazmat.2020.122037.

12. Goss, K. U., Buschmann, J., Schwarzenbach, R. P (2004). Adsorption of organic vapors to air-dry soils: model predictions and experimental validation. Environmental Science \& Technology, 38(13), 3667-3673, DOI: 10.1021/es035388n.

13. Hunter, M. A., Kan, A. T., Tomson, M. B (1996). Development of a surrogate sediment to study the mechanisms responsible for adsorption/desorption hysteresis. Environmental Science \& Technology, 30 (7), 2278-2285, DOI: 10.1016/j.cej.2009.09.013.

14. ISO (International Organization for Standardization) (2016). Evaluation of pore size distribution and porosity of solid materials by mercury porosimetry and gas adsorption - Part 1: Mercury porosimetry, ISO 15901-1:2016, www.iso.org/standard/56005.html.

15. ISO (International Organization for Standardization) (2007). Pore size distribution and porosity of solid materials by mercury porosimetry and gas adsorption - Part 3: Analysis of micropores by gas adsorption, ISO 15901-3:2007, www.iso.org/standard/40364.html.

16. ISO (International Organization for Standardization) (2006). Pore size distribution and porosity of solid materials by mercury porosimetry and gas adsorption - Part 2: Analysis of mesopores and macropores by gas adsorption, ISO 15901-2:2006, www.iso.org/standard/39386.html.

17. Kobayashi, T., Shimizu, Y., Urano, K (2003). Estimation of adsorbed amounts of volatile chlorinated organic compounds to wet soil based on the properties of the compounds and soils. Science of the Total Environment, 301 (1-3), 215-223, DOI: 10.1016/s0048-9697(02)00286-3.

18. Kan, A. T., Fu, G. M., Hunter, M. A., Chen, W., Ward, C. H., Tomson, M. B (1998). Irreversible sorption of neutral hydrocarbons to sediments: experimental observations and model predictions. Environmental Science \& Technology, 32 (7), 892-902, DOI: 10.1021/es9705809. 
19. Kan, A. T., Fu, G. M., Hunter, M. A., Tomson, M. B (1997). Irreversible adsorption of naphthalene and tetrachlorobiphenyl to Lula and surrogate sediments. Environmental Science \& Technology, 31 (8), 2176-2185, DOI: 10.1021/es9601954.

20. Kan, A. T., Fu, G. M., Tomson, M. B (1994). Adsorption/desorption hysteresis in organic pollutant and soil/sediment interaction. Environmental Science \& Technology, 28 (5), 859-867, DOI:

10.1021/es00054a017.

21. Karickhoff, S., Brown, D., Scott, T (1979). Sorption of hydrophobic pollutants on natural sediments. Water Research, 13 (3), 241-248, DOI: 10.1016/0043-1354(79)90201-x.

22. Li, Y., Li, Q., Wu, C., Luo, X., Yu, X., Chen, M (2020). The inappropriate application of the regression langmuir q_m for adsorption capacity comparison. Science of the Total Environment, 699, 134222.1134222.10, DOI: 10.1016/j.scitotenv.2019.134222.

23. MEEPRC (Ministry of Ecology and Environment of the People's Republic of China) (2014). Technical Guideline for Risk Assessment of Contaminated Sites.

http://kjs.mee.gov.cn/hjbhbz/bzwb/jcffbz/201402/t20140226_268358.shtml.

24. MOHURD (Ministry of Housing and Urban-Rural Development of the People's Republic of China) (2009). Code for investigation of geotechnical engineering (revised edition, 2009), GB 50021-2001.

25. McGroddy, S. E., Farrington, J. W (1995). Sediment porewater partitioning of polycyclic aromatic hydrocarbons in three cores from Boston Harbor, Massachusetts. Environmental Science \& Technology, 29 (6), 1542-1550, DOI: 10.1021/es00006a016.

26. Ong, S. K., Lion, L. W (1991). Mechanisms for trichloroethylene vapor sorption onto soil minerals. Environmental Science \& Technology, 20 (1), 180-188, DOI: 10.2134/jeq1991.00472425002000010029x.

27. Park, H (1999). A method for assessing soil vapor intrusion from petroleum release sites: multiphase/multi-fraction partitioning. Global NEST Journal, 1 (3), 195-204.

28. Petersen, L. W., Moldrup, P., Elfarhan, Y. H., Jacobsen, O. H., Yamaguchi, T., Rolston, D. E (1995). The effect of moisture and soil texture on the adsorption of organic vapors. Journal of Environmental Quality, 24(4), 752-759. DOI: 10.2134/jeq1995.00472425002400040028x.

29. Pennell, K. D., Rhue, R. D., Rao, P. S. C., Johnston, C. T (1992). Vapor-phase sorption of p-xylene and water on soils and clay minerals. Environmental Science \& Technology, 26 (4), 756-763, DOI: 10.1021/es00028a014.

30. Rasmussen, A., Gimmi, T., Fluhler, H (1990). Modeling Reactive Gas Uptake, Transport, and Transformation in Aggregated Soils. Soil Science Society of America Journal, 54, 1206-1213. DOI: 10.2136/sssaj1990.03615995005400050002x.

31. Thompson, J. A., Bissett, W. T., Sweeney, A. M (2014). Evaluating geostatistical modeling of exceedance probability as the first step in disease cluster investigations: very low birth weights near toxic Texas sites. Environmental Health, 13, 47. DOI: 10.1186/1476-069X-13-47.

32. Steinberg, S. M., Schmeltzer, J. S., Kreamer, D. K (1996). Sorption of benzene and trichloroethylene (TCE) on a desert soil: effects of moisture and organic matter. Chemosphere, 33 (5), 961-980, DOI: 
10.1016/0045-6535(96)00229-9.

33. Steinberg, S. M., Kreamer, D. K (1993). Evaluation of the sorption of volatile organic compounds by unsaturated calcareous soil from southern nevada using inverse gas chromatography. Environmental Science \& Technology, 27 (5), 883-888, DOI: 10.1021/es00042a010.

34. Smith, J. A., Chiou, C. T., Kammer, J. A., Kile, D. E (1990). Effect of soil moisture on the sorption of trichloroethene vapor to vadose-zone soil at Picatinny Arsenal, New Jersey. Environmental Science \& Technology, 24 (5), 676-683, DOI: 10.1021/es00075a010.

35. US EPA (2015a). Technical Guide for Assessing and Mitigating the Vapor Intrusion Pathway from Subsurface Vapor Sources to Indoor Air. www.epa.gov/vaporintrusion/technical-guide-assessingand-mitigating-vapor-intrusion-pathway-subsurface-vapor.

36. US EPA (2015b). Technical Guide for Addressing Petroleum Vapor Intrusion at Leaking Underground Storage Tank Sites. www.epa.gov/ust/technical-guide-addressingpetroleum-vapor-intrusion-leakingunderground-storage-tank-sites.

37. Unger, D. R., Lam, T. T., Schaefer, C. E., Kosson, D.S (1996). Predicting the effect of moisture on vaporphase sorption of volatile organic compounds to soils. Environmental Science \& Technolog, 30 (4), 1081-1091, DOI: 10.1021/es950065f.

38. Wang, L., Hou, D., Cao, Y., Ok, Y., Tack, F., Rinklebe, J., O'Connor, D (2020). Remediation of mercury contaminated soil, water, and air: A review of emerging materials and innovative technologies. Environment International, 134, 105281. DOI: 10.1016/j.envint.2019.105281.

39. Yardon, B., Sutherland, P., Galin, T., Acher, A. J (1989). Soil Pollution by Petroleum Products, II: Adsorption-Desorption of Kerosene Vapors on Soils. Journal of Contaminant Hydrology, 4, 347-358, DOI: 10.1016/0169-7722(89)90033-8.

40. Zhang, R., Jiang, L., Zhong, M., DeVaull, G., Lahvis, M. A., Ma, J., Zheng, R., Fu, Q (2019a). A source depletion model for vapor intrusion involving the influence of building characteristics. Environmental Pollution, 246, 864-872, DOI: 10.1016/j.envpol.2018.12.035.

41. Zhang, R., Jiang, L., Zhong, M., Han, D., Zheng, R., Fu, Q., Zhou, Y., Ma, J (2019b). Applicability of soil concentration for voc-contaminated site assessments explored using field data from the BeijingTianjin-Hebei urban agglomeration. Environmental Science \& Technology, 53 (2), 789-797, DOI: 10.1021/acs.est.8b03241.

42. Zhang, X., Xu, Z., Wu, M., Qian, X., Lin, D., Zhang, H., Tang, J., Zeng, T., Yao, W., Filser, J., Li, L., Sharma, V.K (2019). Potential environmental risks of nanopesticides: Application of $\mathrm{Cu}(\mathrm{OH}) 2$ nanopesticides to soil mitigates the degradation of neonicotinoid thiacloprid. Environment International, 129, 42-50. DOI: 10.1016/j.envint.2019.05.022.

\section{Figures}



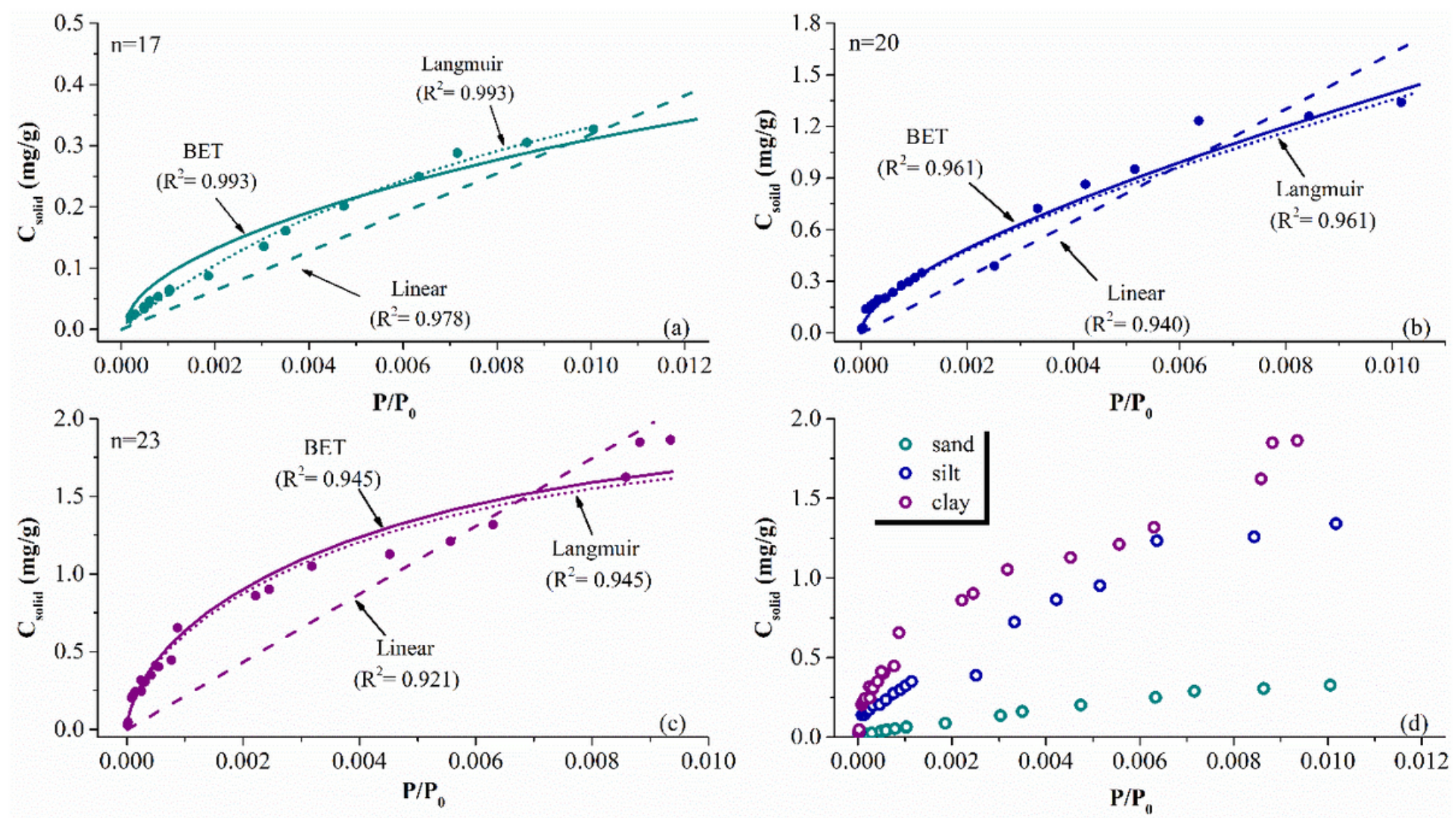

\section{Figure 1}

Three adsorption isotherms (linear, Langmuir and BET) were used to fit the measured headspace data of benzene in (a) sandy soil, (b) silty soil and (c) clayey soil. Panel (d) shows that at same relative vapor pressure, the gas-solid adsorption concentration of clayey soil was higher than that of the other two soils.

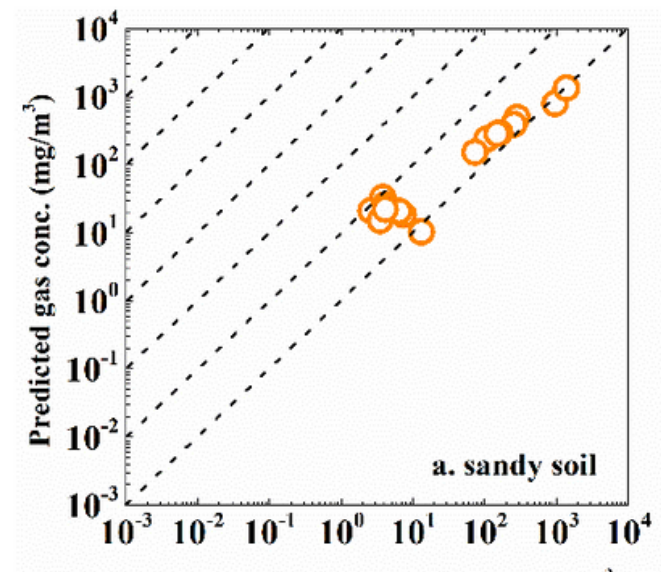

Measured gas conc. of benzene $\left(\mathrm{mg} / \mathrm{m}^{3}\right)$

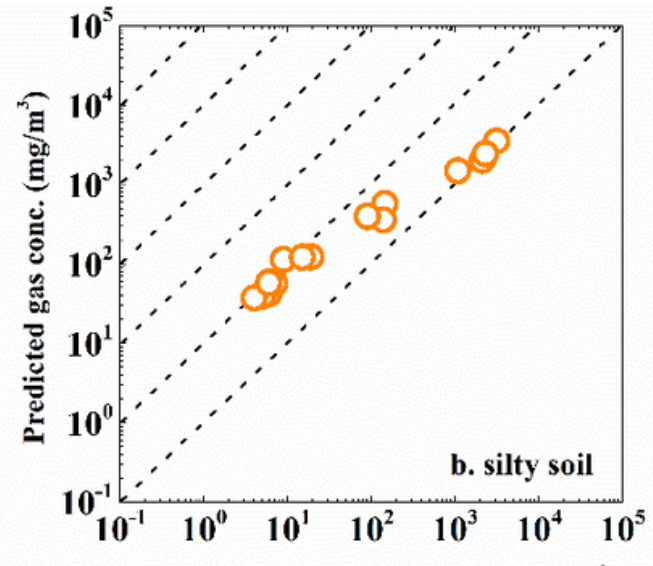

Measured gas conc. of benzene $\left(\mathrm{mg} / \mathrm{m}^{3}\right)$

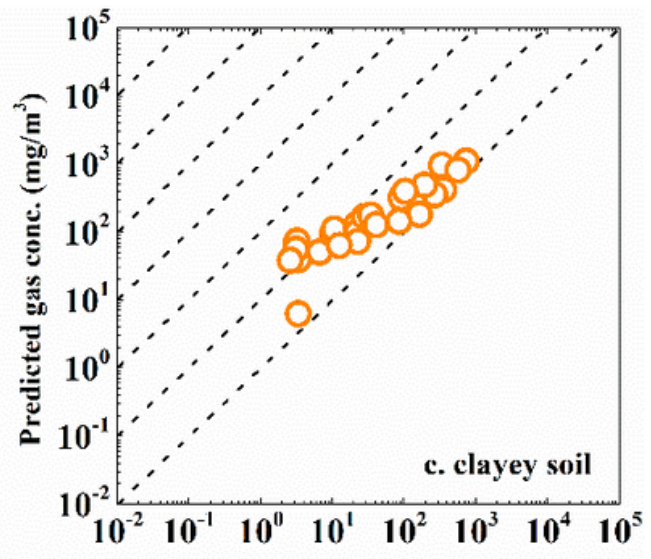

Measured gas conc. of benzene $\left(\mathrm{mg} / \mathrm{m}^{3}\right)$

\section{Figure 2}

The headspace concentrations of benzene were predicted by the MPE model based on the total soil concentrations, and the results were compared with the measured concentrations. The horizontal and vertical axes represent the measured and predicted concentrations, respectively. (a), (b) and (c) show the sandy soil, the silty soil and the clayey soil. 


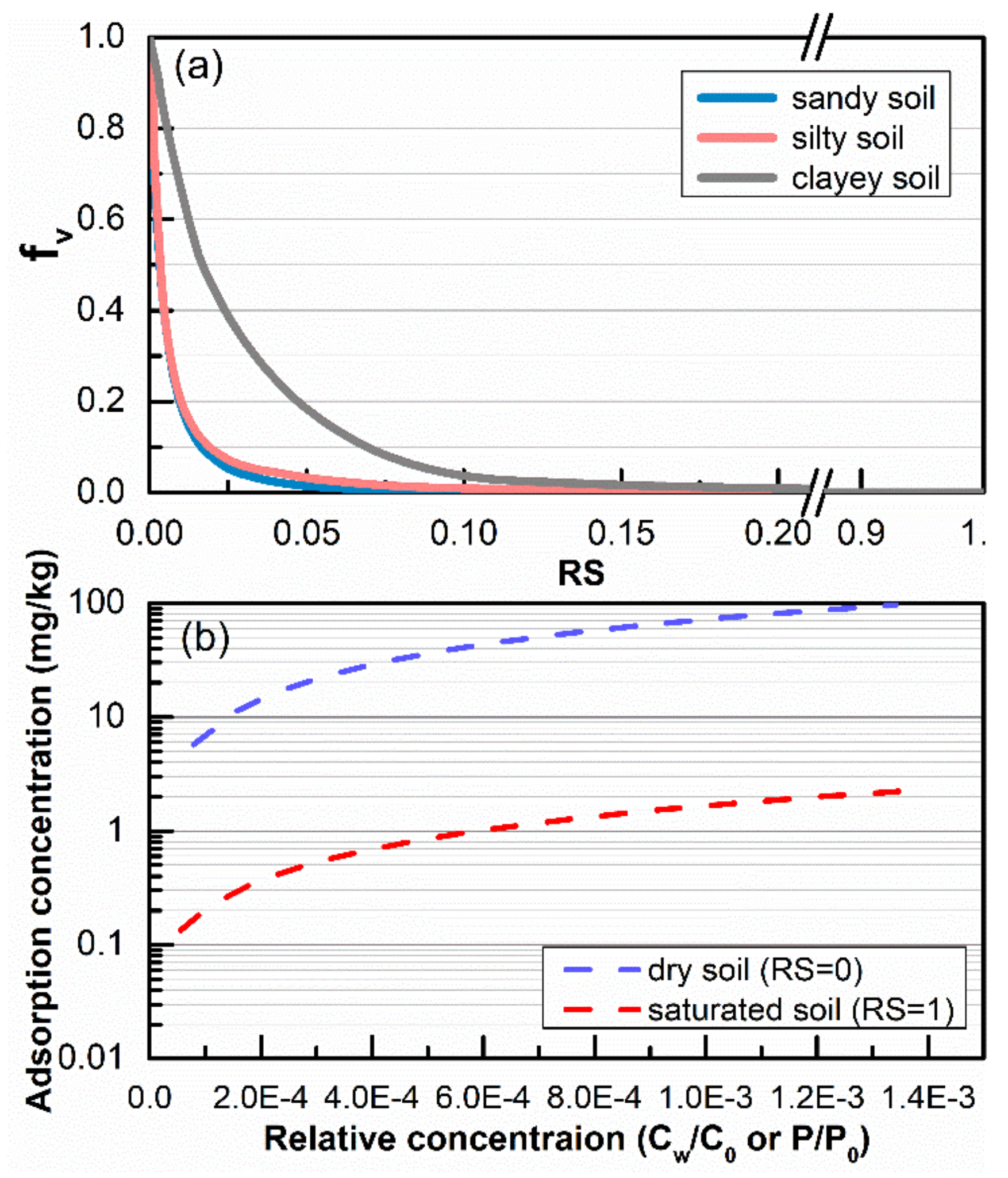

Figure 3

(a) shows the variation in $\mathrm{fv}$ with the RS in soil. When RS increased from 0 to $0.1, \mathrm{fv}$ decreased dramatically from 1 to 0.1 or less in all three soils. Panel (b) shows that the capacity of vapor-solid interface adsorption (dry soil) predicted by the MPE model was approximately two orders of magnitude higher than that of liquid-solid interface adsorption (saturated soil) at the same relative concentration of benzene. 
Sandy soil
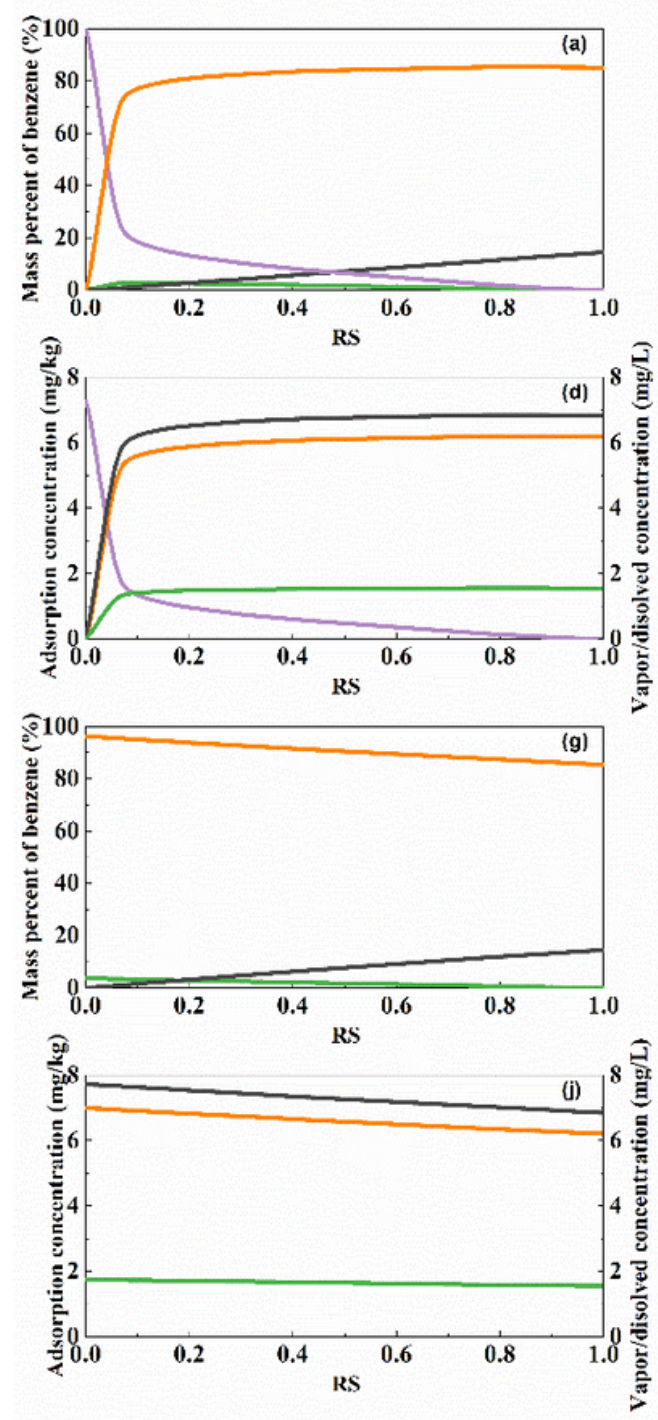

Silty soil
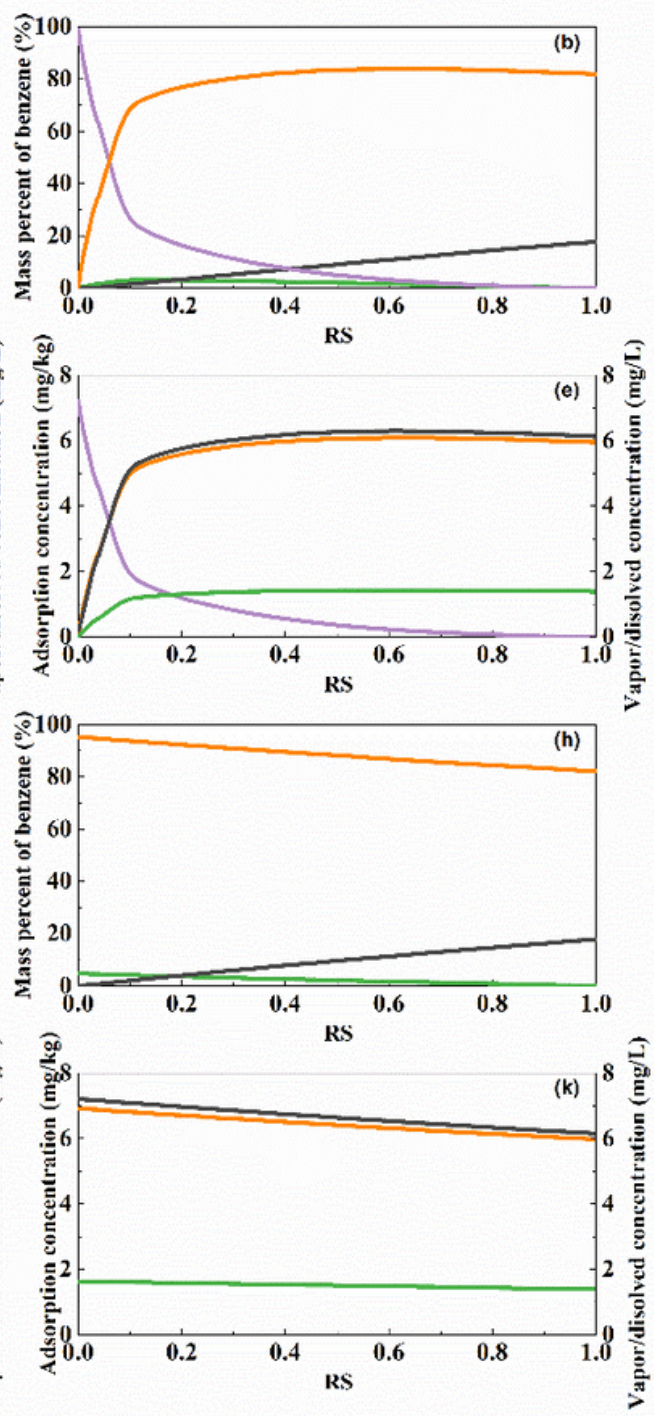

vapor phase

liquid phase
Clayey soil
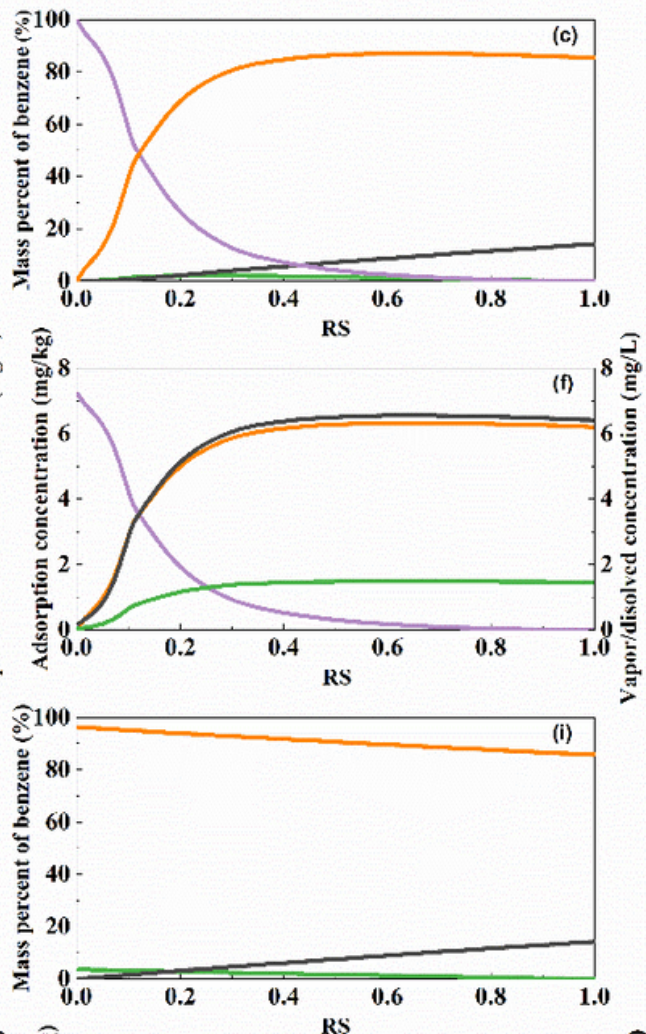

\section{Figure 4}

Mass percent (a-c, g-i) and concentration (d-f, $j-1)$ of benzene in phases taken up by sandy soil, silty soil and clayey soil with different RS values. Panels (a-f) were predicted by the MPE model incorporating both liquid-solid interface adsorption and vapor-solid interface adsorption, and $(\mathrm{g}-\mathrm{l})$ were predicted by the model incorporating only liquid-solid interface adsorption. The double coordinate system is used on the $\mathrm{Y}$-axis of the panels ( $d-f, j-l)$. The unit of the left $Y$-axis is $\mathrm{mg} / \mathrm{kg}$ to show the interface adsorption concentrations. The unit on the right $Y$-axis is $\mathrm{mg} / \mathrm{L}$ to 

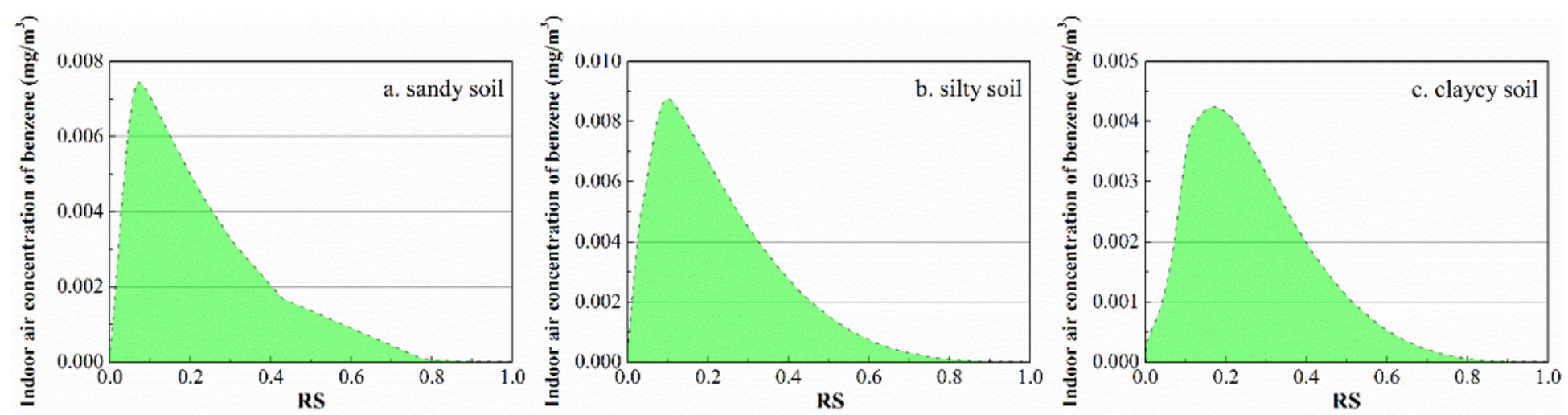

Figure 5

The indoor air concentrations of benzene change greatly with RS in the scenario of vapor intrusion in (a) sandy soil, (b) silty soil and (c) clayey soil.

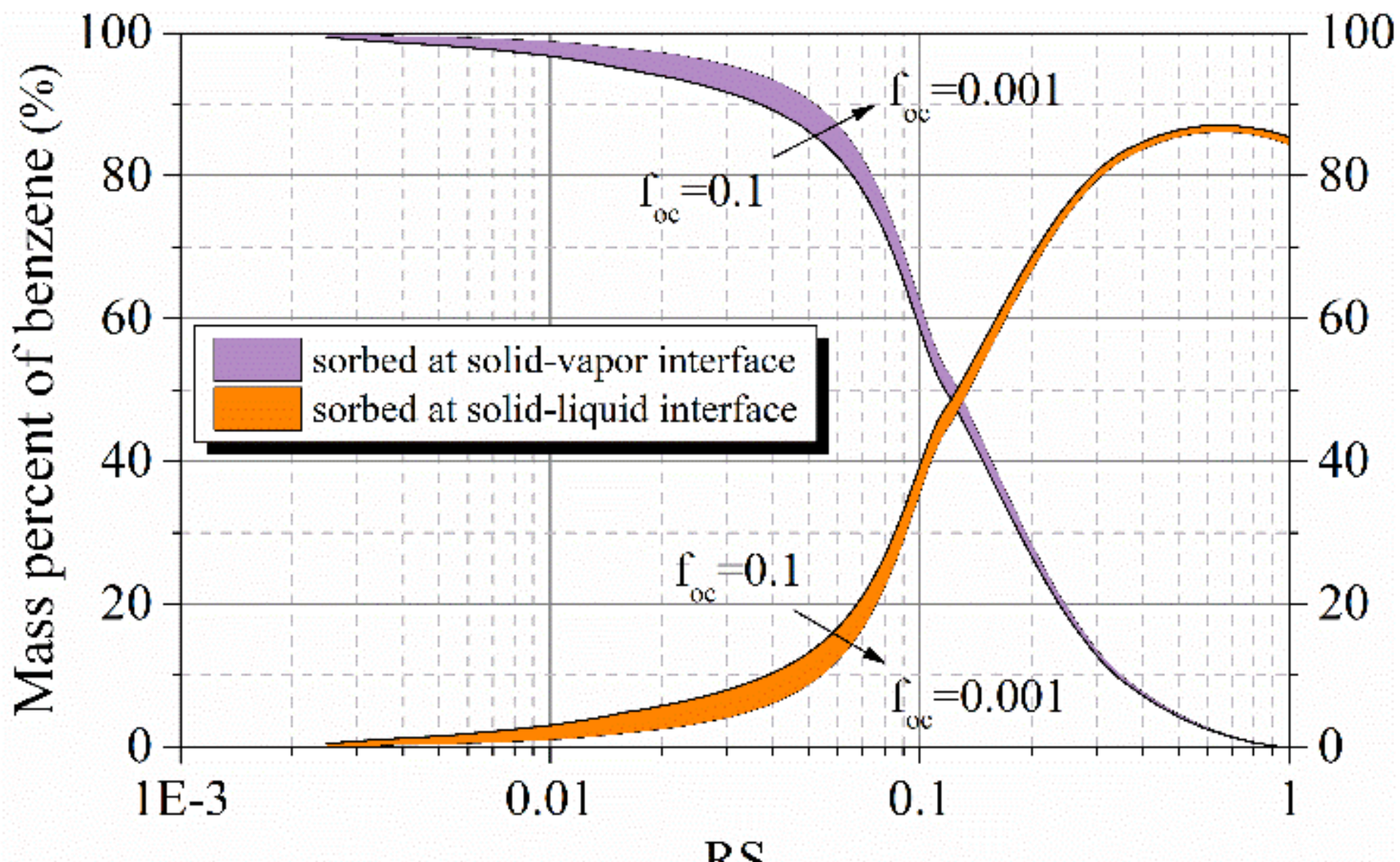

Figure 6

The proportion of masses sorbed at the solid-vapor interface and solid-liquid interface in the clayey soil when increasing fOC from 0.001 to 0.1 .

\section{Supplementary Files}


This is a list of supplementary files associated with this preprint. Click to download.

- SupplementaryMaterial.pdf 